УДК 502.752(470.630)

ИЗУЧЕНИЕ БИОРАЗНООБРАЗИЯ РАСТЕНИЙ ЗАКАЗНИКА РЕГИОНАЛЬНОГО ЗНАЧЕНИЯ «ИРГАКЛИНСКИЙ» СТЕПНОВСКОГО РАЙОНА СТАВРОПОЛЬСКОГО КРАЯ

\author{
Степаненко Е.Е., Зеленская Т.Г., Стукало В.А., Окрут С.В., Друп В.Д. \\ ФГБОУ ВО «Ставропольский государственный аграрный университет», Ставрополь, \\ e-mail: elenapstepanenko@yandex.ru
}

\begin{abstract}
В статье отражены результаты оценки биоразнообразия экосистем территории заказника краевого значения «Иргаклинский» Ставропольского края. Здесь преобладают лесостепи, имеются луговидные степи и ковыльно-типчаково-разнотравные степи. В результате проведенных исследований были выделены следующие типы растительных сообществ: разнотравно-злаковая, ковыльно-бородачевая. Большая часть обследованной территории занята естественной степной растительностью. Обилие и видовой состав разнотравно-злакового типа растительности составляет 20 видов, относящихся к 15 семействам, таким как астровые, вьюнковые, злаковые, крестоцветные, норичниковые, льновые, лютиковые, подорожниковые, зонтичные, жимолостные, яснотковые, гвоздичные, бурачниковые, мальвовые. Выявлено, что состав ковыльно-бородачевого типа растительности состоит из 16 видов, относящихся к 8 семействам, таким как крестоцветные, бобовые, свинчаковые, злаковые, астровые, молочайные, зонтичные, яснотковые. Степень участия отдельных видов в травостое определяли методами учета их относительного обилия. Использовали шкалу Друде, в которой различные степени обилия обозначаются баллами на основе величин наименьших расстояний между особями вида и их встречаемости. На исследуемой территории в ходе эмпиричепских изысканий обнаружено 7 видов сосудистых растений, нуждающихся в охране - включенных в Красную книгу Ставропольского края, относящихся к 4 семействам, таким как бобовые, ирисовые, злаковые, лилейные. В ходе наблюдений выявлено, что в фитоценозах всех пунктов преобладает разнотравная растительность (61 \%), а именно: амброзия полыннолистная, вьюнок полевой, подорожник ланцетолистный, полынь австрийская, резак обыкновенный, скабиоза бледно-желтая, чертополох крючочковый, цикорий обыкновенный, штокроза, бурачок носатый, шандра ранняя и так далее. В спектре групп по продолжительности жизни доминируют многолетние растения, такие как амброзия полыннолистная, вьюнок полевой, ежа сборная, пырей ползучий, цикорий обыкновенный, костер.
\end{abstract}

Ключевые слова: Ставропольский край, заказник краевого значения «Иргаклинский», особо охраняемые природные территории (ООПТ), биоразнообразие

\title{
STUDYING PLANT BIODIVERSITY OF THE ORGANIZATION OF REGIONAL IMPORTANCE «IRGAKLINSKY» OF STEPNOVSKY DISTRICT OF STAVROPOL REGION
}

Stepanenko E.E., Zelenskaya T.G., Stukalo V.A., Okrut S.V., Drup V.D.

Stavropol State Agrarian University, Stavropol, e-mail: elenapstepanenko@yandex.ru

\begin{abstract}
The article reflects the results of assessing the biodiversity of ecosystems in the territory of the reserve of regional significance «Irgaklinsky» of the Stavropol Territory. Forest-steppes prevail here, there are meadow-like steppes and feather-grass-fescue-mixed-grass steppes. As a result of the research, the following types of plant communities were distinguished: forbs-cereal, feather-grass bearded. Most of the surveyed area is occupied by natural steppe vegetation. The abundance and species composition of the herb-herbaceous type of vegetation is 20 species belonging to 15 families such as: aster, bindweed, cereal, cruciferous, norinaceous, flaxseed, buttercup, plantain, umbrella, honeysuckle, clear-headed, clove, borage, mallow. It was revealed that the composition of the feather grass-bearded type of vegetation consists of 16 species belonging to 8 families such as cruciferous, bean, gilt, cereal, aster, euphorbia, umbelliferous, clear-headed. The degree of participation of individual species in the herbage was determined by taking into account their relative abundance. We used the Drude scale, in which various degrees of abundance are indicated by points based on the values of the smallest distances between individuals of the species and their occurrence. In the course of empirical research, 7 species of vascular plants were discovered in the study area that need protection - included in the Red Book of the Stavropol Territory, belonging to 4 families such as legumes, iris, cereal, and lilac. In the course of observations, it was revealed that in the phytocenoses of all points the herbaceous vegetation prevails (61\%), namely ragweed ragweed, field bindweed, plantain lanceolate, Austrian wormwood, common cutter, pale yellow scabiosis, hook thistle, rosacea, chicory, alyssum, chandra early and so on. Perennial plants such as ragweed, field bindweed, field hedgehog, hedgehog creeper, common chicory, bonfire dominate the spectrum of groups by life expectancy.
\end{abstract}

Keywords: Stavropol territory, reserve of regional significance «Irgaklinsky», specially protected natural territories (SPNA), biodiversity

Создание сети особо охраняемых природных территорий Ставропольского края является наиболее эффективной формой сохранения природных комплексов и объектов. Особо охраняемые природные тер- ритории (ООПТ) Ставропольского края занимают всего 1,6\% его площади, и представляют собой островные биогеоценозы среди распаханных и застроенных земель, обреченные на деградацию. Это явно 
не способствует сохранению растительных сообществ региона [1].

С целью сохранения и защиты степных ландшафтов Ставропольского края, как наиболее пострадавшего и угрожаемого типа экосистем степной зоны России, в крае ведется разработка мероприятий по сохранению и рациональному использованию природных ландшафтов. В рамках этой работы необходимо создание новых особо охраняемых природных территорий и поддержка существующих [2].

Цель исследования: изучение биоразнообразия растений заказника краевого значения «Иргаклинский».

\section{Материалы и методы исследования}

Работа выполнена на основе полевых экспедиционных исследований 2014 2019 гг. сотрудниками кафедры экологии и ландшафтного строительства Ставропольского государственного аграрного университета, в результате которых был собран обширный гербарный материал, а также на основе обработки гербарных фондов и анализа литературных источников. Государственный природный биологический заказник краевого значения «Иргаклинский» расположен в двух километрах к юго-востоку от села Иргаклы Степновского муниципального района Ставропольского края.

Географические координаты - 44 $19^{\prime}$ северной широты $44^{\circ} 44^{\prime}$ восточной долготы. Заказник расположен в пределах Курско-Терского окультуренного ландшафта, в междуречье рек Терека и Горькой Балки, провинции полупустынных ландшафтов.

Территория заказника разбита на три функциональные зоны: природоохранная, зона ограниченного природопользования и зона рекреационного использования заказника.

Природоохранная зона. Площадь природоохранной зоны заказника составляет 394,5 га. В данную зону включаются участки северо-восточной и южной частей заказника.

Зона ограниченного природопользования. Площадь зоны составляет 827,5 га. На территории заказника зона размещается по восточной границе и в центральной части.

Зона рекреационного использования заказника. Площадь рекреационной зоны 159 га. Расположена зона в северо-западной и центральной частях заказника, вблизи водоемов. Также включает экологическую тропу, маршрут которой берет свое нача- ло в северной части заказника и проходит по всей его территории.

Растительное биоразнообразие является необходимой составляющей стабильности и функционирования природных экосистем [3]. Данные исследования проведены в полевых условиях. Во время предполевого этапа было проведено изучение литературных и фондовых материалов по району исследований.

Помимо описательного и сравнительно-аналитического методов в работе использовался метод биогеоценотических исследований [4].

Растительность заказника изучена на основе академических и общепринятых методических руководств [5]. Характеристика редких и исчезающих видов, хозяйственно полезных растений дана в работе с использованием специальной литературы.

Видовое разнообразие растительности государственного природного заказника изучалось на площадках 100 м (10х10 м), встречаемость их - на 0,25 м $(п=6)$. Биопродуктивность определялась на 0,5 м $(п=6)$. Обилие видов учитывалось по О. Друде.

При анализе флоры исследуемой территории нами была принята система геоэлементов, разработанная Н.Н. Портениером $(1993,2000)$ и адаптированная для флоры Предкавказья А.Л. Ивановым (1998) добавлением некоторых связующих элементов. Основой географического анализа является составление спектра географических элементов исследуемой флоры (Иванов, 1998).

\section{Результаты исследования и их обсуждение}

Во флористическом отношении исследуемая территория заказника «Иргаклинский» относится к Моздокскому району (М) понтической провинции. Здесь преобладают лесостепи, имеются луговидные степи и ковыльно-типчаково-разнотравные степи [6]. Моздокский флористический район занимает юго-восточную часть Ставропольского края. В него частично входят территории Степновского (за исключением крайней восточной части, Курского (западная часть), Советского (восточная часть), Кировского (восточная чать), Буденновского (южная часть), Нефтекумского (западная часть) районов. Основной тип растительности - ковыльно-типчаковые степи с элементами злаково-полынных и солянковых полупустынь.

В районе насчитывается 723 вида сосудистых растений. Древесная раститель- 
ность, произрастающая на территории заказника, подразделяется на хвойную (сосна крымская) и лиственную (орех грецкий, алыча, смородина, яблоня, облепиха, лох, дуб, унаби, акация, боярышник, облепиха).

В результате проведенных исследований были выделены следующие типы растительных сообществ: разнотравно-злаковая, ковыльно-бородачевая. Большая часть обследованной территории занята естественной степной растительностью.

Обилие и видовой состав разнотравнозлакового типа растительности составляет 20 видов, относящихся к 15 семействам, таким как астровые, вьюнковые, злаковые, крестоцветные, норичниковые, льновые, лютиковые, подорожниковые, зонтичные, жимолостные, яснотковые, гвоздичные, бурачниковые, мальвовые (табл. 1).

Данные таблицы показывают, что такие представители флоры, как амброзия полыннолистная, вьюнок полевой, ежа сборная, зубровка душистая, кардария крупковидная, коровяк мучнистый, лен многолетний, лютик ползучий, осока многолистная, подорожник ланцетолистный, полынь австрийская, резак обыкновенный, скабиоза бледно-желтая, смолевка белая, чернокорень лекарственный, чертополох крючочковый, цикорий обыкновенный, шалфей лекарственный, шток-роза - довольно обильны, средний балл обилия равен cop1.

Следовательно, можно сделать вывод, что на 100 м² произрастает от 10 до 100 особей каждого вида, среднее наименьшее расстояние между особями от 40 до 100 см, а их проектное покрытие составляет 16$25 \%$. Единственный представитель, который имеет средний балл обилия сор2 - пырей ползучий. На одном квадратном метре произрастает не менее 10 особей данного вида, среднее наименьшее расстояние между растениями от 20 до $40 \mathrm{~cm}$, а проектное покрытие варьируется от 25 до $50 \%$. Обилие данного вида можно обосновать тем, что пырей обладает высоким уровнем живучести и плодовитости, он размножается не только семенами, но и корневищами.

Средний балл обилия разнотравно-злакового типа растительности

\begin{tabular}{|l|l|l|}
\hline \multicolumn{1}{|c|}{ Виды растений } & \multicolumn{1}{|c|}{ Латинское название видов } & Средний балл обилия \\
\hline Амброзия полыннолистная & Ambrosia artemisifolia & cop1 \\
\hline Вьюнок полевой & Convolvulus arvensis & cop1 \\
\hline Ежа сборная & Dactylis glomerata & cop1 \\
\hline Зубровка душистая & Hierochloe odorata & cop1 \\
\hline Кардария крупковидная & Lepidium draba & cop1 \\
\hline Коровяк мучнистый & Verbascum lychnitis & cop1 \\
\hline Лен многолетний & Linum perenne & cop1 \\
\hline Лютик ползучий & Ranunculus repens & cop1 \\
\hline Осока многолистная & Carex polyphylla & cop1 \\
\hline Подорожник ланцетолистный & Plantago lanceolata & cop1 \\
\hline Полынь австрийская & Artemisia austriaca & cop1 \\
\hline Пырей ползучий & Elytrigia repens & cop1 \\
\hline Резак обыкновенный & Falcaria vulgaris & cop1 \\
\hline Скабиоза бледно-желтая & Scabiosa ochroleuca & cop1 \\
\hline Смолевка белая & Silene latifolia & cop1 \\
\hline Чернокорень лекарственный & Cynoglossum officinale & cop1 \\
\hline Чертополох крючочковый & Carduus hamulosus & cop1 \\
\hline Цикорий обыкновенный & Cichorium intybus & cop1 \\
\hline Шалфей лекарственный & Salvia officinalis & Alcea rugosa \\
\hline Шток-роза & & \\
\hline
\end{tabular}

*Примечание: cop1 - довольно обильные, среднее наименьшее расстояние от 40 до 100 см, cop2 - обильные, среднее наименьшее расстояние - от 20 до 40 см, сор3 - очень обильные, среднее наименьшее расстояние - не более 20 см. 
Обилие и видовой состав ковыльнобородачевого типа растительности представлены в табл. 2. Он состоит из 16 видов, относящихся к 8 семействам таким как: крестоцветные, бобовые, свинчаковые, злаковые, астровые, молочайные, зонтичные, яснотковые.

Из таблицы видно, что наибольшее количество представителей ковыльно-борадачневой растительности, а именно бурачок носатый, вика узколистная, гониолимон татарский, житняк ширококолосый, козлобородник опушенноносый, костер, люцерна румынская, молочай полевой, овсяница луговая, одуванчик лекарственный, тонконог стройный, шандра ранняя, имеют средний балл обилия.

Из этого следует сделать вывод, что на 100 м $^{2}$ произрастает от 10 до 100 особей каждого вида, среднее наименьшее расстояние между особями от 40 до $100 \mathrm{~cm}$, а их проектное покрытие составляет 16$25 \%$. Типичное растение ксерофитной степи - ковыль имеет средний балл обилия. На одном квадратном метре произрастает не менее 10 особей данного вида, среднее наименьшее расстояние между растениями от 20 до 40 см, а проектное покрытие варьируется от $25 \%$ до $50 \%$. Овсяница валисская (типчак), доминиру- ющий представитель, являющийся очень обильным. На квадратном метре можно встретить от 10 до 100 особей типчака, среднее наименьшее расстояние между особями 0-20 см, а его проектное покрытие колеблется от 51 до $75 \%$. Такое обилие типчака объясняет отсутствие сорной растительности, так как этот дерновой злак препятствует развитию корневой системы сорняков.

На исследуемой территории в ходе эмпирических изысканий обнаружено 7 видов сосудистых растений, нуждающихся в охране - включенные в Красную книгу Ставропольского края, относящихся 4 семействам, таким как бобовые, ирисовые, злаковые, лилейные (табл. 3).

Как видно из таблицы, на территории заказника произрастает достаточно большое разнообразие редких представителей флоры. Вся краснокнижная растительность по среднему баллу обилия варьируется от редких до единичных особей. Количество соответственно не более 10 100 особей на квадратном метре и от 10100 особей на одном гектаре. Среднее наименьшее расстояние между растениями 100-150 см. Проектное покрытие для редких видов - от $6 \%$ до $15 \%$, для единичных - от $1 \%$ до $5 \%$.

Таблица 2

Средний балл обилия ковыльно-бородачевого типа растительности

\begin{tabular}{|c|c|c|}
\hline Виды растений & Латинское название видов & Средний балл обилия \\
\hline Бурачок носатый & Alyssum rostratum & cop1 \\
\hline Вика узколистная & Vicia angustifolia & cop1 \\
\hline Гониолимон татарский & Goniolimon tataricum & cop1 \\
\hline Житняк ширококолосый & Agropyron pectinatum & cop1 \\
\hline Козлобородник опушенноносый & Tragopogon dasyrhynchus & cop1 \\
\hline Костер & Bromus & cop1 \\
\hline Ковыль & Stipa & cop2 \\
\hline Люцерна румынская & Medicago romanica & cop1 \\
\hline Молочай полевой & Euphorbia agraria & cop1 \\
\hline Овсяница валисская (типчак) & Festuca valesiaca & cop1-cop3 \\
\hline Овсяница луговая & Festuca pratensis & cop1 \\
\hline Одуванчик лекарственный & Taraxacum officinale & cop1 \\
\hline Ocot & Sonchus & cop1 \\
\hline Синеголовник полевой & Eryngium campestre & cop1 \\
\hline Тонконог стройный & Koeleria cristata & cop1 \\
\hline Шандра ранняя & Marrubium praecox & cop1 \\
\hline
\end{tabular}

*Примечание: cop1 - довольно обильные, среднее наименьшее расстояние от 40 до 100 см, сор2 - обильные, среднее наименьшее расстояние - от 20 до 40 см, сор3 - очень обильные, среднее наименьшее расстояние - не более 20 см. 
Таблица 3

Средний балл редкой и исчезающей растительности заказника «Иргаклинский»

\begin{tabular}{|l|l|c|c|}
\hline \multicolumn{1}{|c|}{ Виды растений } & \multicolumn{1}{|c|}{ Латинское название видов } & Статус & Средний балл обилия \\
\hline Астрагал коротколопастный & Astragalus Brachylobus & $1(\mathrm{E})$ & sol - sp2 \\
\hline Касатик кожистый & Iris Scariosa Willd. ex Link & $2(\mathrm{~V})$ & sol - sp1 \\
\hline Касатик крымский & Iris taurica Loodd & $3(\mathrm{R})$ & sol - sp1 \\
\hline Ковыль красивейший & Stipa pulcherrima & $2(\mathrm{~V})$ & $\mathrm{sp} 3-\mathrm{cop} 3$ \\
\hline Тюльпан Бибирштейна & Tulipa Bieberateiniana & $2(\mathrm{~V})$ & $\mathrm{sol}-\mathrm{sp} 2$ \\
\hline Тюльпан Геснера & Tulipa Gesneriana L. & $2(\mathrm{~V})$ & $\mathrm{sol}-\mathrm{sp} 2$ \\
\hline Шафран сетчатый & Crocus Reticulatus & $3(\mathrm{R})$ & $\mathrm{sp3}-\mathrm{cop} 1$ \\
\hline
\end{tabular}

*Примечание: 1 (Е) - исчезающий вид, 2 (V) - уязвимый вид, 3 (R) - сокращающийся вид, sol - единично, sp - рассеянно, cop1 - довольно обильно, cop2 - обильно, cop3 - очень обильно.

В ходе наблюдений выявлено, что в фитоценозах всех пунктов преобладает разнотравная растительность (61\%), а именно: амброзия полыннолистная, вьюнок полевой, подорожник ланцетолистный, полынь австрийская, резак обыкновенный, скабиоза бледно-желтая, чертополох крючочковый, цикорий обыкновенный, штокроза, бурачок носатый, шандра ранняя и так далее. В спектре групп по продолжительности жизни доминируют многолетние растения, такие как амброзия полыннолистная, вьюнок полевой, ежа сборная, пырей ползучий, цикорий обыкновенный, костер [7].

\section{Заключение}

Анализ сложившейся ситуации на территории заказника «Иргаклинский» свидетельствует о необходимости разработки системы природоохранных мероприятий, которые будут способствовать поддержанию статуса особо охраняемой природной территории, развитию культурного ландшафта как основы ее формирования [8].

На наш взгляд, необходимо осуществление комплекса мероприятий по природоохранному обустройству территории заказника, который сводится к следующим процедурам: картирование миграционных путей животных для дальнейшей работы по созданию экологических коридоров; минимизация краевого эффекта; проведение регулярных наблюдений за растительными сообществами.

Для сохранения популяций редких видов растений на территории заказника необходимо, прежде всего, сохранять их естественные местообитания (все типы биотопов), не допуская их разрушения чрезмерной хозяйственной деятельностью [9].

\section{Список литературы / References}

1. Гладилин В.А., Юрина В.П., Грицай С.Е. Некоторые проблемы и приоритетные направления развития туризма и рекреации КМВ // Вестник Института дружбы народов Кавказа. Теория экономики и управления народным хозяйством. 2015. № 2 (34). С. 87-94.

Gladilin V.A., Yurina V.P., Gritsay S.E. Some problems and priority directions for the development of tourism and recreation of the CMW // Vestnik Instituta druzhby narodov Kavkaza. Teoriya ekonomiki i upravleniya narodnym khozyaystvom. 2015. № 2 (34). P. 87-94 (in Russian).

2. Друп В.Д. Сравнительный анализ биоразнообразия на территории ООПТ «Александровский» и прилегающих к нему охотничьих угодьях // Современные проблемы науки и образования. 2012. № 6. [Электронный ресурс]. URL: http://science-education.ru/ru/article/view?id=7500 (дата обращения: 10.12.2019).

Drup V.D. A comparative analysis of biodiversity on the territory of the Aleksandrovsky protected areas and adjacent hunting grounds // Modern problems of science and education. 2012. № 6. [Electronic resource]. URL: http://science-education. $\mathrm{ru} / \mathrm{ru} / \mathrm{article} / \mathrm{view}$ id $=7500$ (date of access: 10.12.2019) (in Russian).

3. Бродский А.К. Биоразнообразие. М.: Академия, 2012. $208 \mathrm{c}$

Brodskiy A.K. Biodiversity. M.: Akademiya, 2012. 208 p. (in Russian).

4. Кургузкин М.Г., Кургузкин П.М. Методические аспекты использования фоновых показателей при оценке экологического состояния территорий // Теоретическая и прикладная экология. 2015. № 4. С. 6-11.

Kurguzkin M.G., Kurguzkin P.M. Methodological aspects of using background indicators in assessing the ecological state of territories // Teoreticheskaya i prikladnaya ekologiya. 2015. № 4. P. 6-11 (in Russian).

5. Водопьянова Т.П. Комплексный мониторинг экосистем на особо охраняемых природных территориях (на примере Национального парка «Беловежская пуща») // Труды БГТУ. Экономика и управление. 2011. № 7. C. $114-117$.

Vodopyanova T.P. Integrated monitoring of ecosystems in specially protected natural territories (by the example of the National Park «Belovezhskaya Pushcha») // Trudy BGTU. Ekonomika i upravleniye. 2011. № 7. P. 114-117 (in Russian).

6. Иванов А.Л., Иванов А.А., Чимонина И.В. Эндемики и реликты флоры Ставропольской возвышенности и их значение для построения модели флорогенеза центральной части Северного Кавказа. Ставрополь, 2010. 148 с.

Ivanov A.L., Ivanov A.A., Chimonina I.V. Endemic and relics of the flora of the Stavropol Upland and their importance 
for constructing a model of florogenesis in the central part of the North Caucasus. Stavropol, 2010. 148 p. (in Russian).

7. Зеленская Т.Г., Степаненко Е.Е., Мандра Ю.А., Капаева В.Ю. Изучение фитоценозов заказника «Солёное озеро» Петровского района как индикаторов состояния стабильности степных экосистем // НаукаПарк. 2016. № 8 (49). C. $52-55$.

Zelenskaya T.G., Stepanenko E.E., Mandra Yu.A., Kapaeva V.Yu. A study of the phytocenoses of the Salt Lake reserve of the Petrovsky district as indicators of the state of stability of steppe ecosystems // NaukaPark. 2016. № 8 (49). P. 52-55 (in Russian).

8. Журавлева Л.Л., Хотько Н.И. К значению биологического мониторинга в системе комплексного определения антропогенного воздействия на биоценозы // Проблемы обеспечения химической безопасности в современных услови- ях: сборник статей Международной научно-практической конференции. Пенза, 2015. С. 31-36.

Zhuravleva L.L., Khotko N.I. On the value of biological monitoring in the system of complex determination of anthropogenic impact on biocenoses // Problemy obespecheniya khimicheskoy bezopasnosti v sovremennykh usloviyakh: sbornik statey Mezhdunarodnoy nauchno-prakticheskoy konferentsii. Penza, 2015. P. 31-36 (in Russian).

9. Безгина Ю.А., Лобейко Ю.А., Колосова О.Ю., Гончаров В.Н., Авдеева В.Н. Стратегии региональной экономикоэкологической безопасности // Вестник АПК Ставрополья. 2016. № 3 (23). C. 240-243.

Bezgina Y.A., Lobeyko Yu.A., Kolosova O.Yu., Goncharov V.N., Avdeeva V.N. Strategy of regional economic and environmental security // Vestnik APK Stavropol’ya. 2016. № 3 (23). P. 240-243 (in Russian) 